\title{
Primjena poliuretana u izradi potplata za cipele
}

\author{
Ivona Rajić ${ }^{1}$, Emi Govorčin Bajsić ${ }^{1}$, Tamara Holjevac Grgurić ${ }^{*}$ \\ ${ }^{1}$ Sveučilište u Zagrebu Fakultet kemijskog inženjerstva i tehnologije, Hrvatska \\ ${ }^{2}$ Sveučilište u Zagrebu Metalurški fakultet Sisak, Hrvatska \\ *tholjev@simet.hr
}

Izvorni znanstveni rad

\section{Sažetak}

DOI: $10.34187 / \mathrm{ko} .69 .1 .1$

Dobra obuća trebala bi biti udobna, dugotrajna i primjerena svrsi, a poliuretani (PU) su upravo materijali koji omogućuju dizajnerima da ispune sve ove ciljeve. Poliuretani se u industriji obuće koriste za izradu uložaka i potplata za cipele. Postoje dva tipa PU potplata na osnovi polietera i poliestera. PU potplati na osnovi polietera imaju visoku otpornost na hidrolizu i nisku otpornost na ulje dok PU potplati na osnovi poliestera imaju nisku otpornost na hidrolizu i visoku otpornost na ulje. U ovom radu istražena su toplinska i mehanička svojstva PU elastomera s polieter i poliester poliolom uz različite udjele tvrdog segmenta. Poliuretanski elastomeri priređeni su pretpolimernim postupkom. DSC tehnikom dobivena je djelomična kristalna struktura PU elastomera. Veću kristalnost imaju PU elastomeri s eterskim tipom poliola. Rezultati dobiveni DMA mjerenjem pokazuju da se staklište mekog segmenta povisuje i relaksacijski maksimum se proširuje povećanjem udjela tvrdog segmenta u PU elastomerima na osnovi esterskog tipa poliola uslijed interakcija između uretanske skupine i karbonilne skupine iz poliestera. Mehanička ispitivanja pokazuju porast prekidne čvrstoće s povećanjem udjela tvrdog segmenta.

Ključne riječi: potplat, poliuretanski elastomeri, DSC, DMA, vlačna svojstva

\section{Uvod}

Poliuretan se u industriji obuće počeo koristiti 60 -ih godina i od tada je postao vrlo popularan materijal za proizvođače cipela, budući da omogućuje dobivanje kvalitetne, udobne i izdržljive cipele niske cijene. Poliuretan koji se koristi za izradu potplata cipela ističe se lakoćom otpornošću na abraziju. Poliuretani predstavljaju vrlo kompleksnu, al značajnu skupinu visoko postojanih polimera, te je njihova primjena u ljudskoj djelatnosti vrlo široka zbog njihove specifične strukture. Poliuretani mogu imati različitu strukturu od krute, umrežene do fleksibilne kod elastomernih lanaca. Poliuretanske pjene i TPU elastomeri imaju segmentiranu strukturu, koja je sastavljena od dugih fleksibilnih lanaca (poliola) povezanih aromatskim tvrdim segmentima. Poliuretansk elastomeri predstavljaju skupinu segmentiranih poliuretana, koji su sastavljeni od naizmjeničnih blokova tvrdog i mekog segmenta. ${ }^{1,2}$ Meki segmenti su visokomolekulni polieter ili poliester polioli, koji značajno utječu na elastičnu prirodu poliuretana (fleksibilnost) kao i na svojstva na niskim temperaturama, uslijed niske temperature staklastog prijelaza. ${ }^{3,4}$ Polioli na osnovi polietera općenito daju elastomere koji se odlikuju slabim svojstvima u odnosu na poliuretane na osnovi poliestera. Za razliku od toga elastomeri na osnovi poliola poliesterskog tipa pokazuju niži stupanj kristalnosti.Tvrdi segmenti su linearni reakcijski produkti diizocijanatne komponente niskomolekulnog glikola ili diamina kao produživača lanca .Kod priprave poliuretanskih elastomera koriste se: aromatski, alifatski i cikloalifatsk diizocijanati te različiti alifatski i cikloalifatski niskomolekulni glikoli i diamin kao produživači lanca

Jake polarne veze između $\mathrm{H}$-atoma iz uretanske, odnosno $\mathrm{NH}$-skupine karbonilnog kisika iz susjedne uretanske skupine uvjetuju da tvrde domene djeluju kao umreženje za fleksibilni meki segment .Tvrdi segmenti segregiraju se u tvrde domene, koje mogu imati različiti stupanj sređenosti. Iz prisutnog mekog i tvrdog segmenta, proizlazi dvofazna struktura poliuretana. Poliuretani na osnovi polietera imaju odlična antibakterijska svojstva i savojnu čvrstoću na niskim temperaturama u odnosu na poliester poliuretane. Zbog svojih svojstava poliuretani imaju široku primjenu i sve više se koriste u proizvodnji poliuretanskih pjena, jastuka, sintetske kože te u izradi potplata za cipele. Proizvođači cipela poboljšali su materijale od kojih se proizvode potplati za cipele, kako bi se značajno umanjila udarna sila u odnosu na tradicionalne materijale koji su inače upotrebljavani. Peng i suradnici pokazali su znatno bolju otpornost na udar poliuretanske obuće što je posebno značajno za dizajniranje tenisica za trčanje. Budući da je brzo trčanje postalo jako popularno, a uzastopni snažni udari mogu dovesti do različitih vrsta ozljeda, bitno je da potplati obuće koja se koristi u tu svrhu budu od materijala koji se može deformirati te ograničiti silu tijekom udara pete upijajući energiju. ${ }^{5}$ Sustavi potplata od poliuretana za cipele na tržištu su sada već više od pola stoljeća, te se dijele u dvije kategorije: PU potplati na osnovi polietera koji su vrlo otporni na hidrolizu, te PU potplati na osnovi poliestera s izvrsnom otpornošću na habanje. Izrađuju se i PU potplati kombinacijom ova dva tipa poliola. PU dobivaju se reakcijom izocijanatnog

pretpolimera i poliola. Njihova tvrdoću određuje udio tvrdih segmenata u polimernoj matrici, dok je njihova gustoća rezultat razvoja $\mathrm{CO}_{2}$ nastalog reakcijom izocijanata i vode.

\section{Eksperimentalni dio \\ 2.1. Materijali}

Priređene su četiri serije PU elastomera na osnovi polieterskog (PU ET II i PU ET IV) i poliesterskog (PU ES II i PU ES IV) tipa poliola uz aromatski diizocijanat i različite udjele tvrdog segmenta, odnosno različite odnose $\mathrm{NCO} / \mathrm{OH}$ skupina u pretpolimeru.

Osnovne komponente za pripremu elastomera i njihov omjer izražen kroz omjer $\mathrm{NCO} / \mathrm{OH}$ skupina u pretpolimeru, te udio tvrdog segmenta prikazani su u tablici 1.

Tablica 1. Pregled PU elastomera i njihov sastav

\begin{tabular}{|c|c|c|c|c|c|}
\hline $\begin{array}{c}\mathrm{PU} \\
\text { elastomer }\end{array}$ & $\begin{array}{c}\text { Polyol } \\
\text { (producer) } \\
\text { [commercial } \\
\text { name] }\end{array}$ & $\begin{array}{c}\text { Diisocyanate } \\
\text { (producer) } \\
\text { [commercial } \\
\text { name] }\end{array}$ & $\begin{array}{c}\text { Moleculat } \\
\text { weight } \\
\text { polyol }\end{array}$ & $\begin{array}{l}\text { Wight ration } \\
\text { of hard } \\
\text { segment in } \\
\text { prepolymer }\end{array}$ & $\begin{array}{c}\text { Ratio of } \\
\mathrm{NCO} / \mathrm{OH} \\
\text { in prepolymer }\end{array}$ \\
\hline $\begin{array}{l}\text { PU ET II } \\
\text { PU ET IV }\end{array}$ & $\begin{array}{l}\text { PTMO } \\
\text { (Du Pont } \\
\text { Comp.) } \\
\text { [Terethane } \\
1000]\end{array}$ & $\begin{array}{c}\text { MDI } \\
\text { (Miles) } \\
\text { [Unilink } \\
4200]\end{array}$ & 1000 & $\begin{array}{l}35 \\
52\end{array}$ & $\begin{array}{l}2 / 1 \\
4 / 1\end{array}$ \\
\hline $\begin{array}{l}\text { PU ES II } \\
\text { PU ES IV }\end{array}$ & $\begin{array}{c}\text { PCL } \\
\text { (Union } \\
\text { Carbide } \\
\text { Corp.) } \\
\text { [Tone 0230] }\end{array}$ & $\begin{array}{c}\text { MDI } \\
\text { (Miles) } \\
\text { [Unilink } \\
4200]\end{array}$ & 1250 & $\begin{array}{l}34 \\
51\end{array}$ & $\begin{array}{l}2 / 1 \\
4 / 1\end{array}$ \\
\hline
\end{tabular}

$\mathrm{OCN}-\left\langle\mathrm{O}-\mathrm{CH}_{2}-\right.$ - $-\mathrm{NCO}$

Difenilmetan diizocijanat (MDI)

$4,4^{\prime}$ - difenil metan diizocijanat

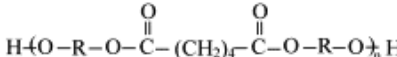

Poliester poliol sa $\mathrm{R} \equiv \mathrm{CH}_{2} \mathrm{CH}_{2}-\mathrm{O}-\mathrm{CH}_{2} \mathrm{CH}_{2}$ $\mathrm{PCL}-$ poli ${ }^{\varepsilon}$ - kaprolakton) glikol

$$
\begin{aligned}
& \mathrm{CH}_{3} \quad \mathrm{CH}_{3} \quad \mathrm{CH}_{3} \\
& \stackrel{\mathrm{C}_{1}}{\mathrm{C} H}-\mathrm{CH}_{2} \mathrm{O}-\left(\mathrm{CH}_{2}-\mathrm{C} H-\mathrm{O}\right)_{\mathrm{n}} \mathrm{CH}_{2}-\stackrel{\mathrm{C}_{3}}{\mathrm{C}}-\mathrm{OH} \\
& \text { Polieter poliol }
\end{aligned}
$$

PTMO - poli(tetrametilen oksid) glikol

\subsection{Priprema uzoraka PU elastomera}

Poliuretanski ,PU ,elastomeri priređeni su pretpolimernim postupkom, koji se odvija u dva stupnja (slika 1) .Prvi stupanj odnosi se na pripravu 
pretpolimera polimerizacijom u masi diizocijanata s poliolom. Korišten je $\mathrm{NCO} / \mathrm{OH}$ omjer $2 / 1$ i $4 / 1$. Diizocijanat je otopljen u reaktoru na temperaturi od $\approx 80^{\circ} \mathrm{C}$ u struji dušika uz snažno miješanje. Nakon toga je diizocijanat ohlađen na $60{ }^{\circ} \mathrm{C}$ i uz miješanje mu je dodan poliol, bez uporabe katalizatora. Kraj reakcije određen je kad je razlika eksperimentalne NCO vrijednosti $\mathrm{u}$ odnosu na izračunatu NCO vrijednost $\approx 1 \%$. Koncentracija NCO u izocijanatu i pretpolimeru mjerena je metodom titracije uz di-(n-butil) amin, ASTM D 2572-80. U drugom stupnju su sintetizirani PU elastomeri reakcijom pretpolimera i produživača lanca, uz NCO / OH omjer 1,05. U tu svrhu je pretpolimer zagrijan na $90{ }^{\circ} \mathrm{C}$ i uz snažno miješanje mu je dodan produživač lanca 1,4-butandiol. Reakcijska smjesa se zatim ubacuje u zagrijani kalup i preša na temperaturi od $100^{\circ} \mathrm{C} u$ vremenu od $30 \mathrm{~min}$ Nakon vađenja iz kalupa elastomeri su 24 sata držani na temperaturi od $105^{\circ} \mathrm{C}$, radi potpunog završetka reakcije, naknadnog umreženja

$$
\text { OCN-R }
$$

Slika 1. Priprava PU elastomera pretpolimernim postupkom.

\subsection{Karakterizacija}

\subsubsection{Dinamičko mehanička analiza ( DMA)}

Dinamičko mehanički analizator DMA 983 proizvođač TA instruments, korišten je za mjerenje primarnih viskoelastičnih funkcija, modula pohrane $E^{\prime}$ i modula gubitka E". Mjerenja su provedena na konstantnoj frekvenciji od $1 \mathrm{~Hz}$ uz amplitudu od $0.2 \mathrm{~mm}$.Brzina zagrijavanja bila je $3^{\circ} \mathrm{C} / \mathrm{min}$, a temperaturno područje od $-100^{\circ} \mathrm{C}$ do $200^{\circ} \mathrm{C}$. Dimenzije uzorka bile su 20,00 x 13,00 x1,00 mm. Tekući dušik korišten je za hlađenje na niske temperature.

\subsubsection{Diferencijalna pretražna kalorimetrija ( DSC )}

DSC mjerenja provedena su na instrumentu Mettler Toledo DSC 822e Brzina zagrijavanja bila je $10^{\circ} \mathrm{C} / \mathrm{min}$. Uzorci mješavina (10 mg) zagrijani su od $25^{\circ} \mathrm{C}$ do $200^{\circ} \mathrm{C}$ brzinom zagrijavanja od $10^{\circ} \mathrm{C} / \mathrm{min}$ i držani su na toj temperaturi $5 \mathrm{~min}$. da se „zaboravi“ toplinska povijest priprave uzorka. Uzorci su nakon toga ohlađeni na $-100^{\circ} \mathrm{C}$ brzinom od $10^{\circ} \mathrm{C} / \mathrm{min}$, nakon čega slijedi ciklus zagrijavanja od $-100^{\circ} \mathrm{C}$ do $200^{\circ} \mathrm{C}$. Iz ova dva ciklusa dobivene su vrijednosti faznih prijelaza. Masu uzorka iznosila je16 mg. Hlađenje na niske temperature provedeno je tekućim dušikom.

\subsubsection{Mehanička svojstva}

Mehanička svojstva provedena su na univerzalnom uređaju za mehanička ispitivanja Zwick 1005. Rastezno ispitivanje provedeno je u skladu sa standardnom metodom DIN 53 455. U program računala unijeti su osnovni parametri koji definiraju ispitivani sustav: vrsta testa (rastezno ispitivanje), temperatura koja je iznosila $230 \mathrm{C}$, relativna vlažnost zraka od $70 \%$, brzina istezanja od $25 \mathrm{~mm} / \mathrm{min}$, dimenzije epruvete od $90.00 \mathrm{~mm} \times 13.0 \mathrm{~mm} \times 1.0$ $\mathrm{mm}$. Provedeno je pet mjerenja za svaki uzorak.

\section{Rezultati i rasprava}

\subsection{Rezultati DSC analize}

Karakteristični toplinski prijelazi prisutni u poliuretanskim (PU) elastomerima su: temperatura staklastog prijelaza, staklište $\left(T_{g}\right)$ mekog segmenta, temperatura taljenja, talište $\left(T_{m}\right)$ nisko i visoko uređenih domena tvrdog segmenta i temperatura kristalizacije, kristalište $\left(T_{c}\right)$ vezanu za kristalnu fazu tvrdog segmenta. Fazni prijelazi u PU elastomerima očitani su iz DSC krivulja zagrijavanja (slika 2a) i DSC krivulja hlađenja (slika 2b), a vrijednosti dobivene iz DSC krivulja prikazane su u tablici 2.
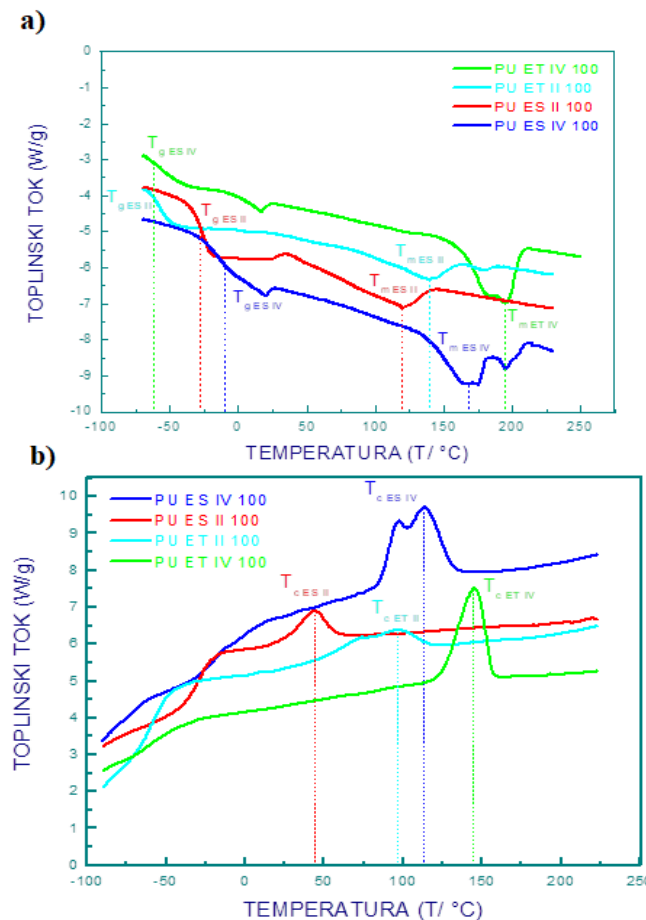

Slika 2. DSC krivulje zagrijavanja a) i hlađenja b) s prikazom staklišta, tališta i kristališta za PU elastomere; PU ET II, PU ET IV, PU ES II i PU ES IV

Endotermni i egzotermni prijelazi na DSC krivuljama ukazuju na djelomičnu kristalastu strukturu PU elastomera. ${ }^{6}$ Staklište u PU ES IV se povisuje povećanjem udjela tvrdog segmenta $\left(\Delta \mathrm{T}_{\mathrm{g}}=10^{\circ} \mathrm{C}\right) \mathrm{u}$ odnosu na PU ES II, kao posljedica smanjene pokretljivosti mekog segmenta. U poliesterskom PU elastomeru postoji bolja mješljivost mekih i tvrdih segmenata, uslijed jačih interakcija esterske i uretanske skupine. Kod PU elastomera s polieterskim tipom poliola postoji veća odijeljenost eterske i uretanske skupine koja se povećava dodatkom tvrdog segmenta, tako da je $\mathrm{T}_{\text {g }}$ za PU elastomere eterskog tipa poliola dobiven na istoj temperaturi od $-56.0^{\circ} \mathrm{C}$ kao kod ET II. Endotermni prijelazi predstavlju tališta $\left(T_{m}\right)$ tvrdog segmenta. Povećanjem udjela tvrdog segmenta povisuje se $T_{m} u$ polieterskim i poliesterskim PU elastomerima. $\mathrm{PU}$ elastomeri s eterskim poliolom imaju više $\mathrm{T}_{\mathrm{m}} \mathrm{u}$ odnosu na PU elastomere s esterskim tipom poliola, zbog njihove veće kristalnosti. ${ }^{7}$ Dobivene vrijednosti za promjenu entalpije taljenja $\left(\Delta \mathrm{H}_{\mathrm{m}}\right)$ povećavaju se $\mathrm{s}$ povećanjem udjela tvrdog segmenta i to značajnije kod PU elastomera eterskog tipa. $\mathrm{Na}$ osnovi vrijednosti $\left(\Delta \mathrm{H}_{\mathrm{m}}\right)$ dobivenih DSC mjerenjem izračunat je stupanj kristalnosti PU elastomera $\left(\chi_{c}\right)$. Za sve PU sustave izračunat je stupanj kristalnosti $\chi_{c}$ preko izraza (1):

$$
\chi_{c}=\frac{\Delta \mathrm{H}_{m}}{\Delta \mathrm{H}_{m}{ }^{o}} \cdot 100 \%
$$

gdje $\Delta \mathrm{H}_{\mathrm{m}}{ }^{0}(\mathrm{~J} / \mathrm{g})$ predstavlja vrijednosti dobivene DSC mjerenjem, a $\Delta \mathrm{H}_{\mathrm{m}} 100$ $(\mathrm{J} / \mathrm{g})$ odgovara $100 \%$ kristalnom PU i iznosi $24,393 \mathrm{~J} / \mathrm{g} .{ }^{8}$ Izračunate vrijednosti stupnja kristalnosti povećavaju se povećanjem udjela tvrdog segmenta i ukazuju na veći stupanj kristalnosti PU elastomera s polieter poliolom. Izmjerene vrijednosti $\Delta \mathrm{Hm}$ kao i stupanj kristalnosti u PU elastomerima prikazani su u tablici 2.

Tablica 2. DSC vrijednosti temperatura toplinskih prijelaza, promjena entalpija taljenja i stupnjevi kristalnosti dobivene DSC mjerenjem za uzorke eterskih i esterskih PU elastomera

\begin{tabular}{|l|c|c|c|c|c|}
\hline & $\mathrm{T}_{g /{ }^{\circ} \mathrm{C}}$ & $\mathrm{T}_{m} /{ }^{\circ} \mathrm{C}$ & $\mathrm{T}_{c /{ }^{\circ} \mathrm{C}}$ & $\Delta \mathrm{H}_{m} / \mathbf{J g}^{-1}$ & $\chi_{c / \%}$ \\
\hline PU ET II & -56.4 & 138.2 & 95.6 & 8.57 & 35.13 \\
PU ET IV & -56.7 & 194.5 & 145.3 & 17.49 & 71.70 \\
\hline PU ES II & -27.0 & 119.6 & 44.02 & 5.24 & 21.48 \\
PU ES IV & -16.4 & 164.4 & 113.9 & 10.26 & 42.06 \\
\hline
\end{tabular}

$\mathrm{T}_{\mathrm{g}}$ - staklište mekog segmenta, $\mathrm{T}_{\mathrm{m}}$ - talište tvrdog segmenta, $\mathrm{T}_{\mathrm{c}}$ - kristalište tvrdog segmenta, $\Delta \mathrm{H}_{\mathrm{m}}{ }^{0}$ - promjena topline taljenja dobivena mjerenjem, $\Delta \mathrm{H}_{\mathrm{m}} 100$ - promjena topline taljenja $100 \%$ kristalnog $\mathrm{PU}(24,393 \mathrm{~J} / \mathrm{g})^{8} \chi_{\mathrm{c}}$ stupanj kristalnosti. 


\subsection{Rezultati DMA analize}

Primjenom tehnike dinamičko mehaničke analize (DMA) određuju se viskoelastična svojstva materijala. Dobiveni relaksacijski prijelazi daju uvid u strukturu materijala. U polimernim mješavinama iz DMA mjerenja može se dobiti uvid u polimer-polimer interakcije i mješljivost komponenata u mješavini. Rezultati su dobiveni praćenjem utjecaja udjela tvrdog segmenta i vrste poliola na svojstva PU elastomera. Na slici 3 a) prikazane su krivulje modula gubitka (E"), a na slici 3 b) krivulje modula pohrane ( $\left.E^{\prime}\right)$ u ovisnosti o temperaturi za PU elastomere, eterskog (PU ET) i esterskog (PU ES) tipa poliola, a u tablici 3 unesene su karakteristične vrijednosti očitane iz krivulja. Kod PU, Tg meke elastomerne faze javlja se na temperaturama ispod sobne temperature i ima niže ili više vrijednosti ovisno o udjelu tvrdog segmenta i vrsti poliola.

a)

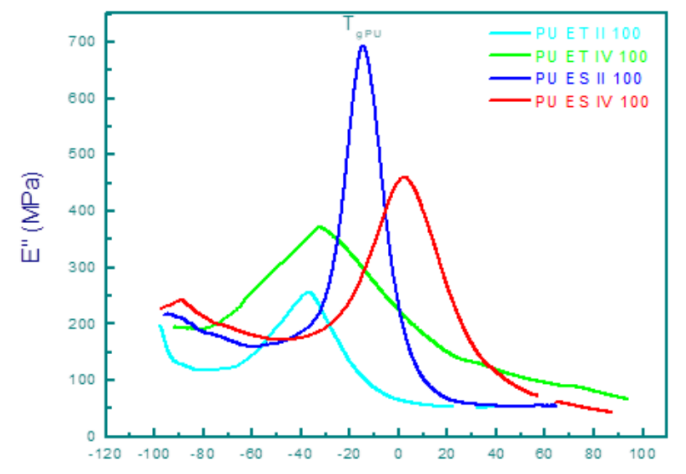

b)

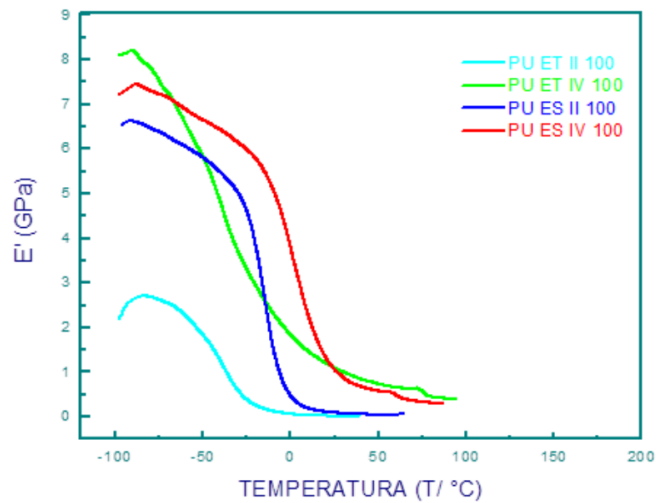

Slika 3. Krivulje a) modula gubitka (E") i b) modula pohrane (E') u ovisnosti o T za PU elastomere; PU ET II, PU ET IV, PU ES II i PU ES IV

Slabe interakcije između eterske i uretanske skupine dovode do odvajanja faza mekog i tvrdog segmenta, što jače dolazi do izražaja dodatkom tvrdog segmenta. Isti rezultat dobiven je DSC analizom. Esterske skupine u poliester PU stvaraju bolje interakcije s uretanskim skupinama, što dovodi do pomicanja $\mathrm{Tg}$ - a na više temperature $\mathrm{i}$ do proširenja relaksacijskog maksimuma kod PU elastomera s većim udjelom tvrdog segmenta (PU ES IV). Povećanje udjela tvrdog segmenta u PU elastomerima eterskog esterskog tipa poliola dovodi do pomicanja modula E' na više temperature što ukazuje na povećanje krutosti PU elastomera porastom udjela tvrdog segmenta.

Tablica 3. Vrijednosti očitane iz krivulja modula $E^{\prime \prime} / T$ i E'/T za $P U$ elastomere eterskog $\mathrm{i}$ esterskog tipa $\mathrm{s}$ manjim i većim udjelom tvrdog segmenta

\begin{tabular}{|l|c|c|}
\hline PU elastomer & $\begin{array}{c}\mathrm{T}_{g P U} \\
\left({ }^{\circ} \mathrm{C}\right)\end{array}$ & $\begin{array}{c}\mathrm{E}_{25}{ }^{\circ} \mathrm{C} \\
(\mathrm{GPa})\end{array}$ \\
\hline PU ET II & -37.1 & 0.02 \\
PU ET IV & -37.7 & 1.094 \\
\hline PU ES II & -14.6 & 0.09 \\
PU ES IV & 2.2 & 1.050 \\
\hline
\end{tabular}

TPU- staklište mekog segmenta u PU elastomerima, $\mathrm{E}^{\prime} 25^{\circ} \mathrm{C}$ - modul pohrane na $25^{\circ} \mathrm{C}$

\subsection{Utjecaj udjela tvrdog segmenta i vrste poliola na mehanička svojstva}

Mjerenjem mehaničkih svojstava materijala, prekidne čvrstoća $\sigma i$ prekidnog istezanje, $\varepsilon$ može se dobiti uvid u adheziju komponenata u mješavini. U ovom dijelu rada bit će opisan utjecaj udjela tvrdog segmenta, kao i vrste poliola na mehanička svojstva PU elastomera. Na slici 4 prikazane su usporedne krivulje naprezanje-istezanje za PU elastomere, a vrijednosti dobivene iz krivulja prikazane su u tablici 4.

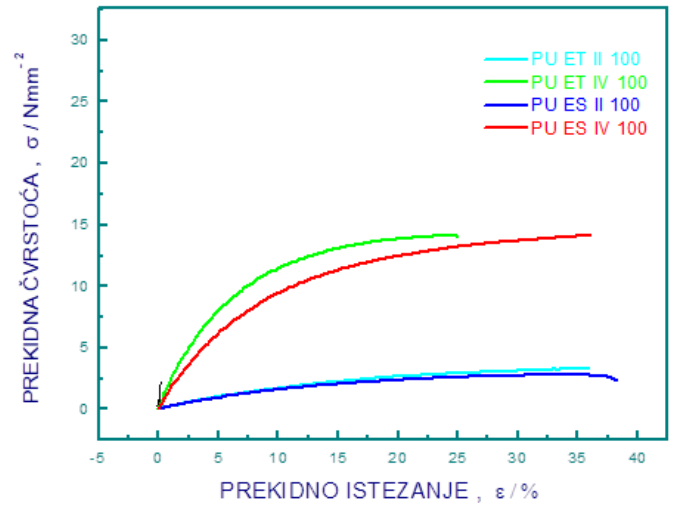

Slika 4. Krivulje naprezanja-istezanja za PU elastomere eterskog esterskog tipa poliola

Woods je u knjizi o poliuretanima napisao da na mehanička svojstva PU ima utjecaj struktura i reaktivnost izocijanata. 9 Poliuretanski elastomeri s aromatskim (MDI) izocijanatom imaju dobra rastezna svojstva zbog velike reaktivnosti i sređene strukture $\mathrm{H}$-veza između uretanskih skupina u tvrdom segmentu. Iz krivulje za PU elastomere na slici 4 vidi se da PU pokazuje malu prekidnu čvrstoću i veliko prekidno istezanje. Povećanje udjela tvrdog segmenta ima za posljedicu porast prekidne čvrstoće i smanjenje prekidnog istezanja u polieterskom (PU ET) i poliesterskom tipu (PU ES) $\mathrm{PU}$ elastomera. PU elastomeri $\mathrm{s}$ eterskim poliolom imaju nešto veće vrijednosti prekidne čvrstoće i niže vrijednosti prekidnog istezanja u odnosu na esterske PU elastomere, zbog pravilne kristalne strukture PTMO-a, koja nastaje tijekom istezanja lanaca makromolekule. ${ }^{10}$

Tablica 4. Vrijednosti mehaničkih svojstava za PU elastomere

\begin{tabular}{|l|c|c|}
\hline PU elastomeri & $\sigma_{R}$ & $\varepsilon_{R}(\%)$ \\
\hline PU ET II & $(\mathrm{MPa})$ & 36.0 \\
PU ET IV & 14.1 & 25.0 \\
& & 38.0 \\
\hline PU ES II & 2.3 & 36.0 \\
PU ES IV & 13.6 & \\
\hline
\end{tabular}

$\sigma_{p}$ - prekidna čvrstoća, ${ }^{\varepsilon_{p}}$ - prekidno istezanje

\section{Zaključak}

Rezultati dobiveni DSC mjerenjem ukazuju na djelomičnu kristalastu strukturu PU elastomera. Uslijed jačih interakcija esterske i uretanske skupine u PU elastomeru na osnovi poliestera dobivena je bolja mješljivost mekih i tvrdih segmenata. Stupanj kristalnosti raste povećanjem udjela tvrdog segmenta kod oba tipa poliola, ali veći stupanj kristalnosti dobiven je za PU elastomere s polieter poliolom. Staklište u PU elastomerima na osnovi esterskog tipa poliola pomiče se na više temperature i do proširenja relaksacijskog maksimuma na krivulji E"/T povećanjem udjela tvrdog segmenta (PU ES IV elastomer). Dobivene vrijednosti modula pohrane $\left(E^{\prime} / T\right)$ rastu povećanjem udjela tvrdog segmenta u PU elastomerima eterskog i esterskog tipa poliola što ukazuje na povećanje krutosti PU elastomera. Također raste i prekidna čvrstoća, ali se smanjenje prekidno istezanje u polieterskom i poliesterskom tipu PU elastomera. PU elastomeri $s$ eterskim poliolom imaju nešto veće vrijednosti prekidne čvrstoće i niže vrijednosti prekidnog istezanja u odnosu na esterske PU elastomere.

\section{Literatura}

[1] S. L. Cooper, A. V. Tobolsky, J Appl Polym Sci 10 (1966) 1837-1844 [2] C.S. Schollenberger, H. Scott, G.R. Moore, RubberWorld 137 (1958) 549-555 [3] S. Sarkar, B. Adhikari, Polym. Degrad. Stabil.73 (2001) 169-175

[4] J. Ferguson, Z. Petrovic, Eur. Polym. 12 (1976) 177-181

[5] Piaolin Penga, Shaolan Dinga, Zhikang Wang, Yifan Zhang, Jiahao Pan (2020), Acute effect of engineered thermoplastic polyurethane elastomer knockoff running footwear on foot loading and comfort during heel-to-toe running, Gait \& Posture, 111

[6] J. Blachwell, C.D. Lee, Advances in Urethane Science and Technology, K.C. Frisch and D.Klempner, Eds., Tehnomic, Stanford, Conn 1994

[7] G.J. Ralf, C. Heijhants, T. G. van Tienen, P. Buma, A.J. Pennings,A.J.Schouten, Biomaterials, 26 (2005) 4219-4228

[8] C.P. Papandopoulow, N.K. Polymer, 39 (1998) 7015

[9] G. Woods, The ICI Polyurethane Book (second ed.), Wiley, (1990)[10] S. Subramani, I. Cheong and J.H. Kim, Progres in Organic Coatings,51, 4 (2004) 328-338 